\title{
Estimation of the average nutrient profile of UK snacks and development of a control snack intervention for utilisation in dietary intervention studies
}

\author{
L. Smith, V. Dikariyanto, L. Francis, M. Rokib, W.L. Hall and S.E. Berry \\ Diet and Cardiometabolic Health Research Group, Faculty of Life Sciences \& Medicine, King's College London, \\ Franklin Wilkins Building, 150 Stamford Street, London, SE1 9NH
}

Snacking has increased in all age groups ${ }^{(1)}$ with a gradual move away from consuming the traditional 3-meals-a-day to a grazing eating style over the past $30 \mathrm{y}^{(2)}$. The average number of snacks consumed is $2 \cdot 55 / \mathrm{d}$ (UK and Ireland) ${ }^{(3)}$, with snacks contributing $20 \%$ of energy requirements ${ }^{(3)}$. Many snack types (crisps, confectionery, bakery products, biscuits, fast food) tend to be high in refined carbohydrate and saturated fat and therefore may significantly contribute to an overall poor diet quality that may increase CVD risk ${ }^{(4)}$.

Nutrition research often focuses on the cardiovascular impact of healthier snack interventions. A nutrient displacement approach is generally used; higher protein, different fatty acid profiles and differing glycaemic loads are compared with regular snacks. However, often there is no true control arm, i.e. the control snack may also change nutrient intake and possibly cardiovascular risk factors compared to baseline during the intervention. Profiling U.K. snacks for their average nutrient composition and applying this to the development of a control snack food will provide a true control that can be used to test the hypothesis that a "healthier" snack will reduce cardiovascular disease risk factors, and thus will allow the effects of nutrient displacement to be studied accurately.

The aims of this study were: a) to calculate the average nutrient profile of snacks consumed by U.K. adults; b) to develop a control snack product to mimic this average snack profile for use in future dietary intervention trials; and c) to conduct a feasibility study to verify that the control snack did not adversely affect serum lipid levels and body composition (precluding its use as a control for a healthier snack).

The snack nutrient profile was calculated by identifying foods consumed as snacks from the National Diet and Nutrition Survey (NDNS) database 2008/9-2011/12 $2^{(5)}$ and classifying them according to the UK and Irish Snacking Report 2014 snacking categories. Mean \% energy contribution of each snack product was calculated to give the nutrient profile of the average UK snack. Using this profile, sweet and savoury snack muffins were developed using formulations calculated using nutrition analysis software (Nutritics, version 4.3). The feasibility study recruited 9 healthy adults aged 30-60 y (regular snackers; $\geq 2$ snacks/d) who consumed the prototype "control" snacks at $20 \%$ of their energy intake for 3-wk. Baseline and endpoint measurements of serum lipids and body composition were taken. The macronutrient profile of the average U.K. snack intake is summarised in the Table.

\begin{tabular}{lccc}
\hline $\begin{array}{l}\text { Macronutrient } \\
\text { (mean \% total } \\
\text { energy) }\end{array}$ & $\begin{array}{c}\text { UK } \\
\text { snack } \\
\text { profile }\end{array}$ & $\begin{array}{c}\text { Overall dietary } \\
\text { intake } \\
\text { (NDNS) }^{(5)}\end{array}$ & $\begin{array}{c}\text { Recommendations for } \\
\text { overall dietary intake* }^{*}\end{array}$ \\
\hline Carbohydrate & $55 \cdot 3$ & $45 \cdot 7$ & 50 \\
Sugars & $23 \cdot 4$ & $19 \cdot 1$ & $\leqslant 5$ \\
Protein & $9 \cdot 8$ & $16 \cdot 5$ & $0 \cdot 75 \mathrm{~g} / \mathrm{kg}$ \\
Total fat & $35 \cdot 6$ & 32.9 & $\leqslant 35$ \\
Saturated fatty acids & $13 \cdot 5$ & $12 \cdot 0$ & $\leqslant 11$ \\
\hline *based on SACN 2015 &
\end{tabular}

There were no significant changes in plasma lipids (total cholesterol: HDL cholesterol ratio, LDL cholesterol or triacylglycerol concentrations), body weight and \% body fat following snack consumption. The control snack developed in this study is appropriate for use in future dietary intervention studies requiring a snack displacement approach.

1. Kerr MA, Rennie KL, McCaffrey TA, et al. (2009). Br J Nutr 101, 122-131.

2. Piernas C \& Popkin BM (2010) J Nutr 140, 325-332.

3. Irish Food Board. Snacking in Ireland and UK. Full Report March 2014

4. Chiuve SE, Fung TT et al. (2012) J Nutr 142, 1009-1018.

5. National Diet and Nutrition Survey. (2008/2009-2011/12). May 2014. Public Health England. 